Московская Наталия Леонидовна, Перова Елена Александровна

\title{
КОМПЬЮТЕРНАЯ БИЗНЕС-СИМУЛЯЦИЯ КАК ФОРМА ИНТЕРАКТИВНОГО МЕТОДА ОБУЧЕНИЯ: ПЕРСПЕКТИВЫ ПРИМЕНЕНИЯ В ОБУЧЕНИИ ИНОСТРАННОМУ ЯЗЫКУ В ВЫСШЕЙ ШКОЛЕ
}

Актуальность выбранной темы обусловлена необходимостью интеграции элементов интерактивного и цифрового обучения в методологию профессионально ориентированного обучения иностранному языку. Целью данного исследования является определение эффективности применения компьютерной бизнес-симуляции как формы интерактивного обучения иностранному языку в высшей иколе. В статье представлена последняя классификация обучающих компьютерных игр Генерального Директората Евросоюза по вопросам образования и культуры, рассмотрены наиболее популярные современные обучаючие бизнес-симулячии и продемонстрирована их образовательная иенность. Важсным выводом этого исследования является то, что компьютерная бизнес-симуляция позволяет студентам применить функциональные знания в ходе иноязычной профессиональной деятельности.

Ключевые слова: интерактивное обучение, компьютерная бизнес-симуляция, имитационное моделирование, обучение профессиональному иностранному языку, профессиональная лингводидактика, профессиональные навыки.

\section{Natalia Moskovskaya, Elena Perova \\ COMPUTER BUSINESS SIMULATION AS AN INTERACTIVE FOREIGN LANGUAGE TEACHING TOOL: POTENTIAL FOR APPLICATION IN A HIGHER EDUCATION CURRICULUM}

The relevance of the chosen topic is due to the need to introduce interactive educational tools in the methodology of teaching foreign language for professional purposes. The objective of this paper is to assess the effectiveness of computer business simulation as an interactive foreign language teaching method in a university curriculum. The article provides the updated classification of educational digital games introduced by the Directorate General for Education and Culture of the European Commission. The implementation of some popular educational computer business-simulations is outlined and their educational value in a university setting is discussed. The important finding of this research is the ability of simulation to encourage students to apply their functional expertise to professional communication in a foreign language.

Key words: interactive teaching, computer business simulation, simulation modeling, foreign language for professional purposes teaching, professional linguodidactics, professional expertise.

Bведение / Introduction. Модернизация современной системы языкового образования в высшей школе невозможна без создания учебных материалов нового поколения с обязательным включением в них элементов интерактивного и цифрового обучения. Необходимость трансформации традиционных подходов профессиональной лингводидактики, методологии обучения иностранному языку для будущей специальности, заставляет по-новому взглянуть не только на процесс преподавания, но и обратить внимание на мировоззрение и потребности современного поколения 
Современное поколение молодых людей, родившихся в 80-90-х гг., называемое учеными поколением «Y», интернет-поколением, поколением «Хай-тек», существует условно в двух реальностях: виртуальной и реальной $[6$, с. 74]. На наш взгляд, именно компьютерная бизнес-симуляция способствует тесному взаимодействию виртуальной и реальной действительности, позволяя обучаемым применить и совершенствовать специальные знания и навыки в виртуальном учебном пространстве, воссоздающим предметное и социальное содержание будущей профессиональной деятельности. Следовательно, целью настоящего исследования является определение эффективности применения компьютерной бизнес-симуляции как формы интерактивного, профессионально ориентированного обучения иностранному языку в эпоху интенсивного развития цифровых технологий и интернет-культуры.

Maтериалы и методы /Materials and methods. Теоретико-методологическую базу исследования составляют труды по теории формирования профессиональной компетентности посредством использования симуляционных технологий таких западных ученых, как M. Alfridge, B. S. Bell, K. J. Cohen, R. W. Cook, A. H. Feinstein, M. Frese, A. Grösler, A. M. Kanar, N. Keith, S. W. Kozlovski, E. A. Kludge, D. C. Lane, S. Mann, C. Musslewhite, K. Naicker, A. P. Raia, E. Rhenman, C. O. Swift, J. Vincent, J. Wolfe, D. M. Yorke.

Проведение исследования и описание полученных результатов осуществлялись с использованием методов анализа научно-теоретической литературы по проблеме исследования, сравнительного анализа и обобщения научно-теоретических положений и эмпирических данных.

Результаты и обсуждение / Results and discussion. Как известно, интерактивные методы подразделяются на неимитационные: проблемное обучение, практическое занятие, семинар, дискуссия - и имитационные: деловая игра, игровое проектирование, кейсовый метод [5, с.175]. Также формы и методы интерактивного обучения можно разделить: на дискуссионные (диалог, групповая дискуссия, разбор ситуаций из практики); игровые (деловые, ролевые, организационно-деятельностные игры); тренинговые формы проведения занятий, включающие дискуссионные и игровые методы обучения $[4$, с. 76$]$.

Проанализировав основные формы и методы интерактивного обучения, мы синтезировали на их основе следующее определение: компьютерная бизнес-симуляция - это специальная форма интерактивного, тренингово-игрового, профессионально ориентированного обучения в разнообразных по уровню сложности бизнес-ситуациях, смоделированных с помощью компьютерных устройств.

Компьютерная бизнес-симуляция, по сути, является имитационной деловой игрой, в основе которой лежит компьютерное моделирование, воссоздающее предметное и социальное содержание будущей профессиональной деятельности обучаемых. Являясь инструментом игрового взаимодействия, бизнес-симуляция позволяет активизировать иноязычную коммуникативную деятельность в рамках определенной профессиональной деятельности. Бизнес-симуляция способствует формированию бизнес-мышления и пониманию специфики бизнеса: принципов формирования конкурентных преимуществ предприятия на общем и локальных рынках, отдельных бизнес-процессов: логистики, закупок, продаж, обслуживания. Посредством бизнес-симуляции происходит совершенствование управленческих навыков, умений принимать управленческие решения на основе анализа финансовых показателей, умения выстраивать стратегию развития предприятия, гарантирующую рост его доходов, формируется клиенто-ориентированная установка. Бизнес-симуляция учит студентов применять теоретические знания на практике в процессе генерации групповых решений, осуществлять наблюдение и сообщать о его результатах в виде обратной связи, оценивая эффективность профессиональных действий друг друга [2, с. 74].

Согласно исследованиям Р. Карникау и Ф. Макэлроу, человек помнит $10 \%$ прочитанного; $20 \%$ - услышанного; $30 \%$ - увиденного; $50 \%$ - увиденного и услышанного; $80 \%$ - того, что говорит сам; $90 \%$ - того, до чего дошел в деятельности (рис. 1) [3, с. 12]. 


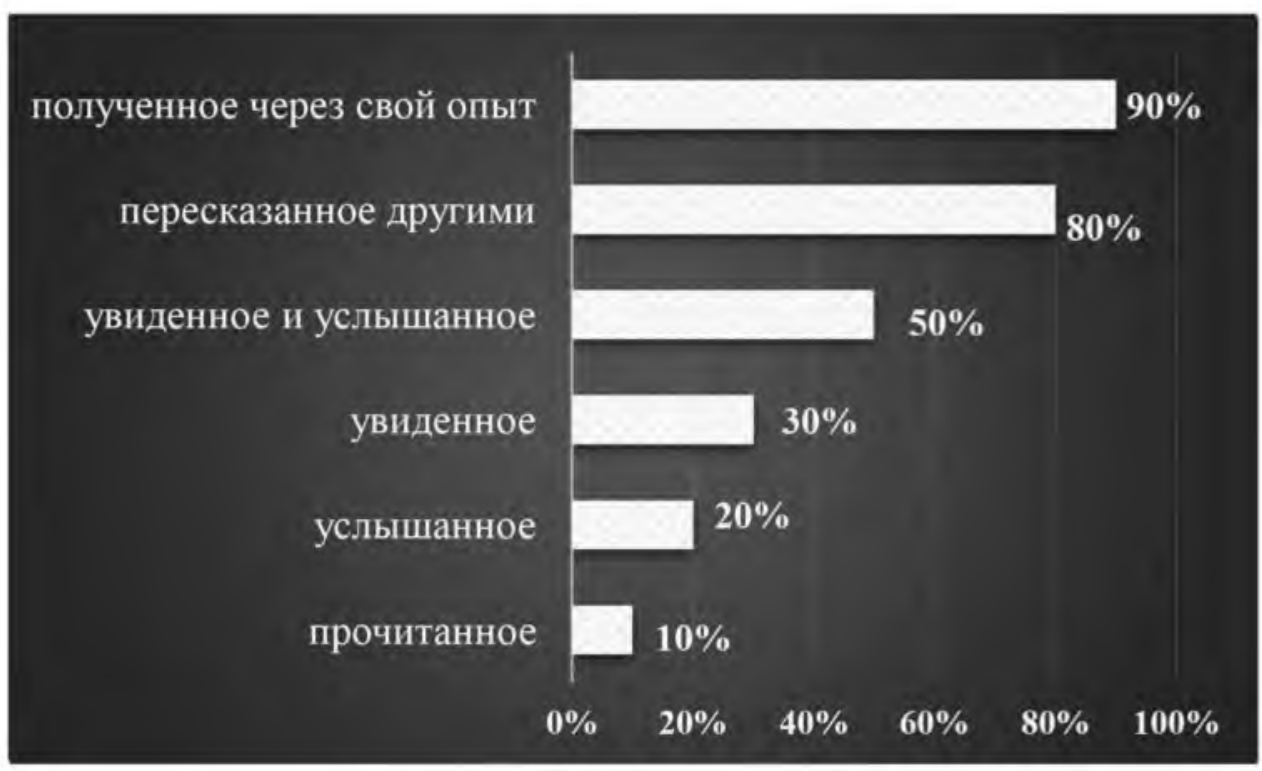

Рис. 1. Диаграмма закономерности усвоения информации обучаемыми в процентах, Согласно Р. Карникау и Ф. Макэлроу

На наш взгляд, данные исследования Р. Карникау и Ф. Макэлроу только подтверждают тот факт, что преобладающим аспектом в обучении профессиональному иностранному языку должна быть практика. Суть компьютерной бизнес-симуляции как раз и заключается в сочетании теоретических знаний с практической деятельностью в условиях реального времени. Симуляция служит идеальным средством обучения на основе аутентичных материалов, высоко интерактивных сценариев, «обучения через действие / практику» 'learning by doing' [13, с. 10].

Согласно Д. Лэйну, симуляция позволяет обучить профессиональным знаниям, навыкам и умениям в сжатые сроки. Традиционно большая часть управленческих навыков формируется постепенно в процессе многолетней профессиональной деятельности, на фоне чего симуляция выгодно выделяется, являясь средством ускоренного обучения [12, с. 561].

С точки зрения Р. Кука, К. Свифта и Д. Лэйна, обучение, основанное на бизнес-симуляции, обеспечивает более сложноорганизованную и реалистичную среду по сравнению с другими педагогическими технологиями [12, с. 561]. Одним из явных преимуществ симуляции является то, что она воссоздает многогранную модель реальности, в рамках которой происходит профессиональная самоидентификация обучающегося. В отличие от обучения, основанного на лекциях и прочих текстовых материалах, симуляция позволяет студентам применить свои знания и навыки в решении реальных задач и моментально получить результат.

Ряд таких американских ученых, как Б. Белл, А. Канар, С. Козловски, утверждают, что иммерсия, т. е. погружение, является одним из основных преимуществ симуляции. Важно отметить, что иммерсия не обязательно означает физическую реалистичность компьютерной бизнес-симуляции, а скорее воссоздание базовых психологических процессов, типичных для моделируемой ситуации [12, с. 562].

Почему же компьютерная бизнес-симуляция является более эффективной стратегией, чем стажировка или традиционные методы обучения? Причина заключается в ее способности влиять на аффективную сферу, вызывая такие эмоции, как удовольствие, волнение, гнев и радость. Традиционное обучение преимущественно воздействует на когнитивную сферу обучения без должного внимания к эмоциональному компоненту [9, с. 9]. 
Более того, традиционные образовательные средства, такие как лекции и просмотр видео, демонстрируют эффективные управленческие решения, но не позволяют осуществить их применение на практике. В свою очередь, достаточно сложно использовать реальные бизнес-ситуации в качестве обучающих сценариев в силу множества контекстуальных факторов, затрудняющих мгновенную оценку результатов деятельности. К. Коэн, Э. Ренман, Р. Кук, К. Свифт утверждают, что обучение, основанное на симуляции, создает упрощенную и управляемую реальность. Бизнес-симуляция поддерживает баланс между сложностью реальной профессиональной деятельности и простотой традиционных образовательных стратегий, создавая реалистичную образовательную среду, стимулирующую критическое мышление и применение теоретических знаний на практике [12, с. 562].

Бизнес-симуляция обеспечивает относительно безрисковую среду для опытного обучения. Обучение, основанное на симуляции, воссоздает возможные кризисные ситуации, позволяя студентам направления «Экономика и управление» применить стратегии реагирования на непредвиденные обстоятельства, не опасаясь негативных последствий ни для себя, ни для организации. Следовательно, по мнению Н. Кейт и М. Фрезе, обучающиеся вероятно будут более свободно экспериментировать с различными стратегиями в подобной безрисковой среде [12, с. 563].

Такие западные ученые, как М. Меррилл, Г. Моррисон, Ч. Райгелут, Ф. Штейн, считают симуляцию формой самоконтролируемого обучения. Исследователи полагают, что самоконтроль важен для повышения эффективности обучения. Компьютерная бизнес-симуляция позволяет студентам выбрать удобный для них темп, акцентировать внимание на непонятных аспектах и отдельных опциях игры [12, с. 563].

Применение компьютерной бизнес-симуляции в качестве компонента рабочей программы дисциплины «Иностранный язык в сфере профессиональной коммуникации» способствует не только повышению мотивации, интереса, вовлеченности и энтузиазма студентов в отношении изучаемого материала, но и реализации основных принципов профессиональной лингводидактики. Согласно принципу межкультурной коммуникации, иностранный язык выступает средством профессионального иноязычного взаимодействия в бизнес-симуляции. Принцип опережающей специализации реализуется в бизнес-симуляции как форме обучения на базе аутентичных профессионально ориентированных материалов и заданий. Принцип селективности позволяет минимизировать лингвистический материал до предела, необходимого для продуктивной профессиональной деятельности будущего специалиста $[1$, с. 6]. Принцип автономности позволяет обучающемуся самостоятельно выбирать и применять бизнес-симуляцию вне рамок лингвистического минимума или рабочей программы дисциплины.

Согласно принципу междисциплинарности, бизнес-симуляция является средством формирования межпредметных профессиональных навыков и умений. Для успешного участия в бизнес-симуляции студентам необходимы не только знания профессиональной направленности, но и знания основ психологии, управления человеческими ресурсами, финансового и стратегического менеджмента, маркетинга, информационных технологий и т. д.

В соответствии с принципом интернационализации, выбранная бизнес-симуляция должна отвечать требованиям рабочей программы дисциплины «Иностранный язык в сфере профессиональной коммуникации», предусматривающей лингвистический минимум владения иностранным языком для эффективного профессионального общения. Например, рабочая программа дисциплины «Иностранный язык» для направления «Сервис и туризм» определяет лингвистический минимум уровня В1 (свободное владение языком), необходимый для ведения формальной беседы с клиентами по телефону, при личном контакте, в электронной переписке.

Реализация принципа многоуровневости и модульности в компьютерной бизнес-симуляции позволяет студентам по мере успешного ее выполнения переходить на более сложные уровни. Принцип проблемности предусматривает включение в бизнес-симуляцию сложных профессио- 
нальных заданий. Например, бизнес-симуляции, предполагающие отказ от единственно правильного решения, допускают наличие нескольких точек зрения и оперируют такими понятиями, как «множественность интерпретаций», «интуиция», «нелинейность» [1, с. 7].

Компьютерная бизнес-симуляция является формой интерактивного обучения на основе игр (Game-Based Learning), реализующего применение компьютерных игр в образовательных целях. В силу интенсивного развития технологий игровой индустрии становится все более сложно составить полную и точную классификацию компьютерных игр. Тем не менее, какой жанр игры будет наиболее эффективным в определенном образовательном контексте, зависит от ряда параметров, таких как предмет обучения, учебный материал, педагогические задачи.

Мы исследовали образовательный потенциал некоторых популярных обучающих компьютерных бизнес-симуляций, представленных на сайте Business Simulation Games - BSG (www. businesssimulationgames.com) [10, c. 4]. На наш взгляд, дидактическая ценность таких известных бизнес-симуляций, как Build Your Own Business (BYOB), Business Tycoon Online, Eutopia, Virtual Leader, Wall Street Survivor заключается в их способности формировать лидерские качества, навыки управления сложными финансовыми и бизнес-процессами, учить поиску и отбору информации, ее анализу и синтезу [7, с. 353]. Данные симуляции представляют собой эффективное средство активизации профессиональной иноязычной деятельности студентов, обучающихся по направлению «Экономика и управление».

Ряд таких бизнес-симуляций, как the Guest Experience sim, Cesim Hospitality, the Hotel Simulation (HOTS), HotelSim, the SLATE (Strategic Learning and Training Experience) Hotel, Virtual Hotel (Virtel), позволяют обучающимся направления «Сервис и туризм» приобрести навыки управления гостиничным бизнесом в виртуальном пространстве посредством иноязычной коммуникации с целевой аудиторией $[8, \mathrm{c} .13]$.

Далее нами была представлена классификация обучающих компьютерных игр и их образовательного потенциала, созданная под эгидой Генерального Директората Евросоюза по вопросам образования и культуры (таблица 1) [13, с.11].

Таблица 1

Классификация обучающих компьютерных игр

\begin{tabular}{|c|c|c|}
\hline Тип игры & Примеры игр & Образовательная ценность \\
\hline Экшн-игра & $\begin{array}{l}\text { Violent (жестокие игры): Counter } \\
\text { Strike, Call of Duty, Battlefield, } \\
\text { Tomb Rider, 1942; America's Army, } \\
\text { Brothers in Arms, Gears of War, } \\
\text { Callout } 3 \text {. Non violent (нежестокиe } \\
\text { игры): Mirrors Edge, Super Mario } \\
\text { Bros, Re-Mission, Need for Speed, } \\
\text { Mario Galaxy, Pac-Man, Asteroids. }\end{array}$ & $\begin{array}{l}\text { Формирует навыки планирования ресурсов, } \\
\text { пространственной ориентировки, способству- } \\
\text { ет погружению }\end{array}$ \\
\hline Ролевая игра & $\begin{array}{l}\text { Fable, Dragon Age: Origins, Dragon } \\
\text { Age 2, Neverwinter Nights, The } \\
\text { Elder Scrolls, Baldur's Gate. }\end{array}$ & $\begin{array}{l}\text { Активизирует сотрудничество и управление } \\
\text { ресурсами, способствует развитию навыков } \\
\text { стратегического мышления и решения проблем }\end{array}$ \\
\hline $\begin{array}{l}\text { Приключенческая } \\
\text { игра }\end{array}$ & $\begin{array}{l}\text { Braid, Portal; Monkey Island, } \\
\text { Maniac Mansion, Zelda; Indigo } \\
\text { Prophecy, Heavy Rain; King's } \\
\text { Quest; Spyro, Callout } 3 \text {. }\end{array}$ & $\begin{array}{l}\text { Совершенствует исследовательские умения и } \\
\text { навыки решения проблем }\end{array}$ \\
\hline Стратегия & $\begin{array}{l}\text { Civilization, Lemmings, Starcraft } 2 \text {, } \\
\text { Supreme Commander, Age of } \\
\text { Empires, Dune II, Warcraft, } \\
\text { Command and Conquer. }\end{array}$ & $\begin{array}{l}\text { Способствует развитию навыков планирова- } \\
\text { ния и решения проблем, пониманию сложно- } \\
\text { го набора правил, воссозданию исторических } \\
\text { событий }\end{array}$ \\
\hline
\end{tabular}




\begin{tabular}{|c|c|c|}
\hline Тиі игры & Примеры игр & образовательная ценность \\
\hline Симуляция & $\begin{array}{l}\text { The Sims, Sim City, Angry Birds, } \\
\text { World of goo; RollerCoaster Tycoon, } \\
\text { Theme Hospital; F-16 Allied Forces, } \\
\text { Il-2 Sturmovik, X-plane, Flight } \\
\text { Simulator. }\end{array}$ & $\begin{array}{l}\text { Воссоздает реальность в виртуальном } \\
\text { пространстве, позволяет осуществлять } \\
\text { исследование и подтверждение теории через } \\
\text { наблюдение различных взаимодействий и их } \\
\text { результатов }\end{array}$ \\
\hline $\begin{array}{l}\text { Боевая и } \\
\text { спортивная игры }\end{array}$ & $\begin{array}{l}\text { Fifa Soccer Saga, Pro Evolution } \\
\text { Soccer, NBA Live, Tekken (saga), } \\
\text { Street Fighter (saga). }\end{array}$ & $\begin{array}{l}\text { Активизируют командную работу, развивают } \\
\text { зрительно-моторную координацию и реакцию }\end{array}$ \\
\hline
\end{tabular}

Для определения целесообразности проведения компьютерной бизнес-симуляции необходимо понять, кому необходим подобный метод обучения и какой материал должен быть в основе симуляции (рис. 2).

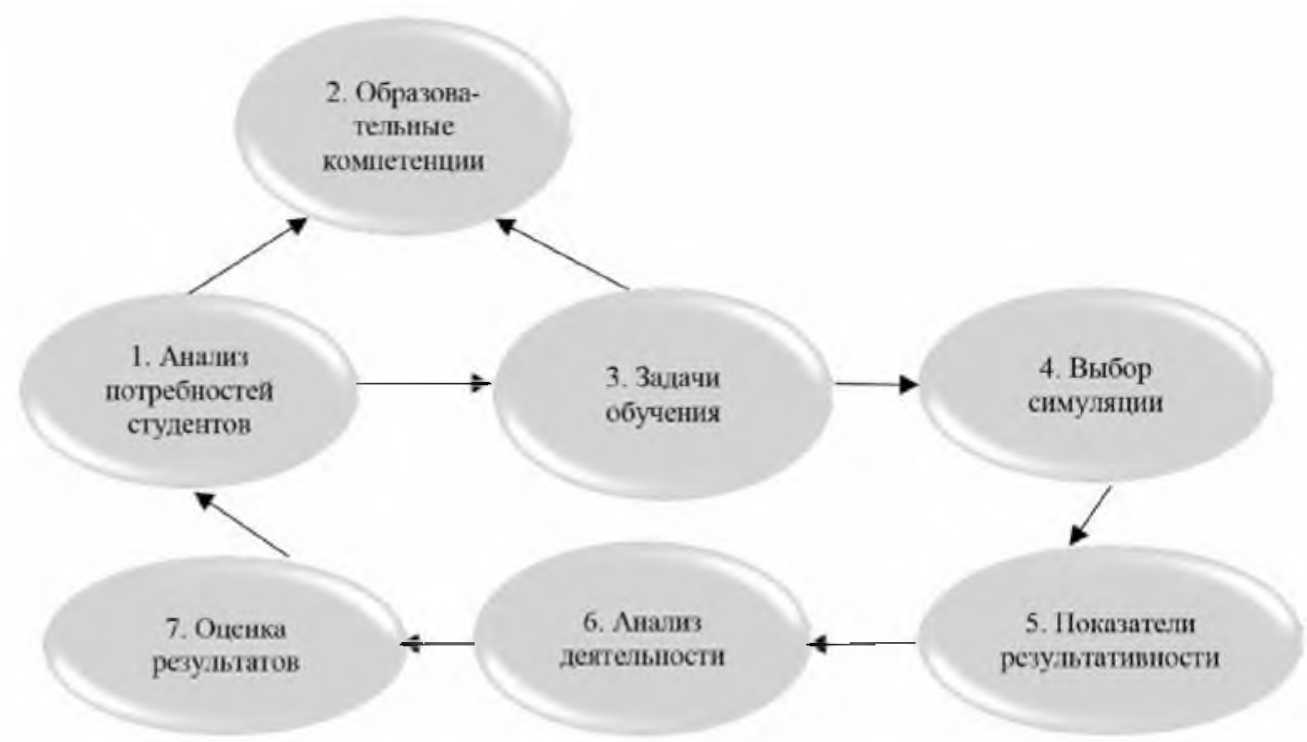

Рис. 2. Этапы успешного проведения симуляции для обучения менеджменту

Во-первых, важно провести анализ потребностей, позволяющий оценить и описать знания, навыки и умения отобранной группы студентов [12, с. 564]. Следующим этапом станет подготовка на основе полученных сведений о знаниях, навыках и умениях студентов. На данном этапе выявляются предполагаемые результаты симуляции.

По мере идентификации общей цели обучения необходимо определить общие или специальные задачи. Специальной задачей может выступать точное оформление отчета или заполнение формы, в то время как общая задача заключается в формировании умений межличностной коммуникации и ведения переговоров. Затем следует выбрать такую симуляцию, которая обладала бы потенциалом для активизации необходимых компетенций. Далее определяются критерии эффективности деятельности для оценки результатов. Выбранные критерии применяются для сбора данных и для оценки результатов в соответствии с конкретными стандартами и целями, сформулированными на третьем этапе. На финальном этапе дается конструктивная оценка на основе показателей результативности [12, с. 565].

В качестве шкалы оценки в рамках дебрифинга / рефлексии преподаватели могут использовать классификацию Ч. Масселвайта (таблица 2). Он разделил симуляции на четыре уровня как для студентов, так и для преподавателей-инструкторов, т. е. фасилитаторов. Действия участников 
оценивалось в соответствии со степенью взаимодействия, уровнем предсказуемости результатов и потенциалом для возникновения конфликтных и эмоциональных ситуаций. Критерии результативности действий фасилитатора включают организаторские навыки, время на подготовку к симуляции, сложность выполнения симуляции, уровень ожидаемой обратной связи, наблюдательность и навыки дебрифинга $[11$, с. 3$]$.

Таблица 2

Классификация критериев уровней симуляции

\begin{tabular}{|c|c|c|c|c|c|c|c|}
\hline \multirow[b]{2}{*}{ Критерий } & \multicolumn{3}{|c|}{ Взаимодействие участников } & \multicolumn{4}{|c|}{ Знания и навьки фасилитатора } \\
\hline & $\begin{array}{l}\text { Взаимодей- } \\
\text { ствие } \\
\text { участников }\end{array}$ & $\begin{array}{c}\text { Предсказуе- } \\
\text { мость } \\
\text { результата }\end{array}$ & $\begin{array}{c}\text { Эмоцио- } \\
\text { нальная } \\
\text { активация } \\
\text { / потенцил } \\
\text { конфликта }\end{array}$ & $\begin{array}{c}\mathbf{y}_{\text {добоство }} \\
\text { применения }\end{array}$ & $\begin{array}{c}\text { Индивидуаль- } \\
\text { ная поведен- } \\
\text { ческая оценка }\end{array}$ & $\begin{array}{l}\text { Групповая } \\
\text { оценга }\end{array}$ & $\begin{array}{c}\text { Набшода- } \\
\text { тельность, } \\
\text { организаци- } \\
\text { оншые умения } \\
\text { и навьпи } \\
\text { дебрифинга }\end{array}$ \\
\hline Уровень 1 & Интерактивное & Высокая & $\begin{array}{l}\text { Маловероятно, } \\
\text { но возможно }\end{array}$ & $\begin{array}{l}\text { Незначительно } \\
\text { сложное }\end{array}$ & Нет & Возможна & Начальный \\
\hline Уровень 2 & \begin{tabular}{|l|} 
Высоко- \\
интерактивное
\end{tabular} & Средняя & $\begin{array}{l}\text { Отчасти } \\
\text { вероятно }\end{array}$ & $\begin{array}{l}\text { Несколько } \\
\text { сложное }\end{array}$ & Минимальна & $\begin{array}{l}\text { Вполне } \\
\text { вероятна }\end{array}$ & Средний \\
\hline Уровень 3 & Сложное & Низкая & \begin{tabular}{|l|} 
Очень \\
вероятно
\end{tabular} & $\begin{array}{l}\text { Умереннно } \\
\text { сложное }\end{array}$ & Возможна & Да & Хороший \\
\hline Уровень 4 & Сложное & Низкая & Ожидаемо & Сложно & Ожидаема & Да & $\begin{array}{l}\text { Очень } \\
\text { хороший }\end{array}$ \\
\hline
\end{tabular}

На наш взгляд, данная классификация Ч. Масселвайта позволяет определить причинно-следственную связь, лежащую в основе эффективности или неэффективности симуляции. Симуляции третьего и четвертого уровней с характерной для них сложноорганизованной интерактивностью предполагают способность студента принимать самостоятельные управленческие решения, полагаясь на финансовые и технические показатели. Подобные симуляции способствуют развитию навыков анализа и синтеза информации, финансовой грамотности, в меньшей степени уделяя внимание навыкам иноязычного взаимодействия в различных бизнес-сценариях. Симуляции первого и второго уровней с интерактивной и высоко интерактивной средой более эффективны для активизации навыков иноязычной деятельности. Бизнес-симуляции с высокой и средней предсказуемостью результатов более предпочтительны в рамках преподавания дисциплины «Иностранный язык в сфере профессиональной коммуникации〉, направленной на развитие базовых профессиональных компетенций с преимушественным акцентом на иноязычных умениях.

В силу того что эмоциональный компонент изначально заложен в структуре компьютерной бизнес-симуляции, уровневая классификация данного критерия не является столь значимой для преподавания профессионального иностранного языка. Также рекомендованы симуляции с дружественным пользовательским интерфейсом, характерные для первого и второго уровней. Кроме того, в рамках преподавания дисциплины «Иностранный язык в сфере профессиональной коммуникации〉 крайне важна возможность индивидуальной оценки иноязычной деятельности студентов, характерной для симуляций третьего и четвертого уровней. Следовательно, симуляции третьего и четвертого уровней являются более сложными, но и более эффективными для преподавания иностранного языка, начиная с пятого семестра обучения, когда уже сформированы базовые лингво-профессиональные компетенции студентов.

Одним из значимых результатов бизнес-симуляции является способность студентов применять междисциплинарные знания в процессе принятия решений. В процессе реализации бизнес-симуляции у студентов формируется понимание специфики бизнеса и бизнес-мышление, тренируются управленческие навыки, совершенствуются отдельные профессиональные компе- 
тенции. Использование стратегии бизнес-симуляции в преподавании английского языка позволяет активизировать навыки устной иноязычной коммуникации. Исследование показало, что межличностное взаимодействие, коммуникация, командная работа и обмен идеями повышается и улучшаются благодаря бизнес-симуляции. Симуляция позволяет студентам применить теоретические знания на практике в процессе генерации индивидуальных и групповых решений.

Заключение / Conclusion. Практика использования компьютерной бизнес-симуляции в высшей школе, последипломном и корпоративном обучении насчитывает более 40 лет [2, с. 75]. В России большей популярностью пользуются настольные бизнес-симуляции. В частности, такие известные компании, как ЕВРАЗ-Россия, Метинвест, Северсталь, Centravis, MTC, Дюпон Россия и многие другие используют настольные бизнес-симуляции для развития компетенций своих руководителей высшего и среднего звена $[2$, с. 76$]$. Необходимо внедрять и расширять практику использования компьютерных бизнес-симуляций в высшей школе, не ограничиваясь традиционными настольными бизнес-симуляциями. На наш взгляд, в настоящее время важно более активно адаптировать возможности компьютерной бизнес-симуляции к целям высшего образования в качестве формы интерактивного обучения профессиональному иностранному языку

Компьютерная бизнес-симуляция не только способствует активизации иноязычной коммуникативной деятельности, но и является инструментом формирования качеств, обеспечивающих успешность выполнения профессиональных обязанностей в иноязычной среде. К таковым относятся навыки управления, командного взаимодействия, разрешения конфликтов, эффективная коммуникация, грамотное выражение мыслей, принятие самостоятельных решений, понимание специфики бизнеса и бизнес-мышления. Преобладающим аспектом в обучении в высшей школе должна быть практика. Компьютерная бизнес-симуляция позволяет студентам приобрести практические навыки управления различными бизнес-процессами. Будущий руководитель, получивший обучение на базе бизнес-симуляции, не только владеет навыками иноязычной профессиональной коммуникации, но и знает, чем занята каждая служба его предприятия, умеет делать все, что делают его служащие.

\section{ЛИТЕРАТУРА И ИНТЕРНЕТ-РЕСУРСЫ}

1. Анзина Т. И. Подготовка кадров для региональной индустрии гостеприимства: синергетический подход // Вестник ассоциации вузов туризма и сервиса. 2017. № 11 (1). С. 3-12.

2. Бородиенко А. В. Бизнес-симуляция vs традиционные педагогические технологии: эффекты использования // Образовательные технологии (г. Москва). 2014. № 4. С. 71-77.

3. Гоева В. В., Миронов К. Е. Использование активных и интерактивных методов обучения при изучении технических дисциплин в вузах // Карельский научный журнал. 2016. № 2 (15). С. 11-15.

4. Ермакова Т. И., Ивашкин Е. Г. Проведение занятий с применением интерактивных форм и методов обучения. Нижний Новгород: Нижегород. гос. техн. ун-т им. Р. Е. Алексеева, 2013. 158 с.

5. Петренко М. А., Баталина Е. А. Интерактивные методы обучения на уроках иностранного языка // Образование и наука в современных условиях. 2016. № 2-1 (7). С. 173-176.

6. Щеглова Л. В., Плужникова Н. Н., Саенко Н. Р. Интерактивные технологии в преподавании гуманитарных дисциплин: в поисках современной модели обучения // Вестник ассоциации вузов туризма и сервиса. 2017. № 11 (2). С. 73-78.

7. Blazic A. J., Ribeiro C., Fernandes J., Pereira J., Arh T. Analysing the required properties of business simulation games to be used in e-Learning and education. // Intelligent Information Management. 2012. No. 4. Pp. 348-356.

8. Cesim Hospitality Simulation User Manual, 2012. P. 39. URL: http://webd.savonia.fi/home/saselka/ lataukset/cesimpelaaja.pdf (accessed 10 January 2019).

9. Donovan L. The use of serious games in the corporate Sector. Dublin: Learning Innovation Learnovate Centre, 2012. P. 38. URL: https://www. learnovatecentre.org/wpcontent/uploads/2013/06/Use_of_Serious_ Games_in_the_Corporate_Sector_PRINT_FINAL.pdf (accessed 12 December 2018). 
10. Gronstedt A. Simulation-Based Learning: The Rise of the PlayStation Professionals. The eLearning Guild, 2018. P. 12. URL: https:/www.elearningguild.com/publications/119/simulation-based-learning-the-riseof-the-playstation-professionals/ (accessed 15 December 2018).

11. Penfold P., Kong W. F., Lee W. K. A. VIRTEL - Teaching hospitality with a virtual hotel e-simulation. Paper presented at APERA 2006: Asia-Pacific Educational Research Association International Conference (Hong Kong, 28-30 November, 2006). P. 16. URL: https://www.researchgate.net/publication/27412138 (accessed 11 November 2018).

12. Salas E., Wildman J, Piccolo R. Using simulation-based training to enhance management education // Academy of Management Learning \& Education. 2009. Vol. 8. No. 4. Pp. 559-573.

13. Torrente J. Production of creative game-based learning scenarios: a handbook for teachers. ProActive public deliverable. Education and Culture DG. Lifelong Learning Programme, 2010. P. 43. URL: http:// www.ub.edu/euelearning/proactive/documents/handbook_creative_gbl.pdf (accessed 14 December 2018).

\section{REFERENCES AND INTERNET RESOURCES}

1. Anzina T. I. Podgotovka kadrov dlya regionalnoj industrii gostepriimstva: sinergeticheskij podhod (Staff training for the regional hospitality industry: synergetic approach) // Vestnik associacii vuzov turizma $i$ servisa. 2017. No. 11 (1). S. 3-12.

2. Borodienko A. V. Biznes-simulyaciya vs tradicionnye pedagogicheskie tekhnologii: ehffekty ispolzovaniya (Business simulation vs traditional teaching methods: application experience) // Obrazovatelnye tekhnologii (g. Moskva). 2014. No. 4. S. 71-77

3. Goeva V. V., Mironov K. E. Ispolzovanie aktivnyh i interaktivnyh metodov obucheniya pri izuchenii tekhnicheskih disciplin $v$ vuzah (The use of active and interactive teaching methods when studying technical disciplines at universities) // Karelskij nauchnyj zhurnal. 2016. No. 2 (15). S. 11-15.

4. Ermakova T. I., Ivashkin E. G. Provedenie zanyatij s primeneniem interaktivnyh form i metodov obucheniya (The use of interactive methods and techniques in education). Nizhnij Novgorod: Nizhegorod. gos. tekhn. un-t im. R. E. Alekseeva, 2013. S.158.

5. Petrenko M. A., Batalina E. A. Interaktivnye metody obucheniya na urokah inostrannogo yazyka (Interactive methods in teaching foreign language) // Obrazovanie i nauka v sovremennyh usloviyah. 2016. No. 2-1 (7). S. 173-176.

6. Shcheglova L. V., Pluzhnikova N. N., Saenko N. R. Interaktivnye tekhnologii v prepodavanii gumanitarnyh disciplin: v poiskah sovremennoj modeli obucheniya (Interactive technologies in teaching the Humanities: in search of modern models of teaching) // Vestnik associacii vuzov turizma i servisa. 2017. No. 11 (2). S. 73-78.

7. Blazic A. J. Analysing the required properties of business simulation games to be used in e-Learning and education / A. J. Blazic, C. Ribeiro, J. Fernandes, J. Pereira, T. Arh // Intelligent Information Management. 2012. No. 4. Pp. 348-356.

8. Cesim Hospitality Simulation User Manual, 2012. P. 39. URL: http://webd.savonia.fi/home/saselka/ lataukset/cesimpelaaja.pdf (accessed 10 January 2019).

9. Donovan L. The use of serious games in the corporate Sector. Dublin: Learning Innovation Learnovate Centre, 2012. P. 38. URL: https://www. learnovatecentre.org/wpcontent/uploads/2013/06/Use_of_Serious_ Games_in_the_Corporate_Sector_PRINT_FINAL.pdf (accessed 12 December 2018).

10. Gronstedt A. Simulation-Based Learning: The Rise of the Play Station Professionals. The eLearning Guild, 2018. P. 12. URL: https://www.elearningguild.com/publications/119/simulation-based-learning-the-riseof-the-playstation-professionals/ (accessed 15 December 2018).

11. Penfold P., Kong W.F., Lee W.K.A. VIRTEL - Teaching hospitality with a virtual hotel e-simulation. Paper presented at APERA 2006: Asia-Pacific Educational Research Association International Conference (Hong Kong, 28-30 November, 2006). P. 16. URL: https://www.researchgate.net/publication/27412138 (accessed 11 November 2018).

12. Salas E., Wildman J, Piccolo R. Using simulation-based training to enhance management education // Academy of Management Learning \& Education. 2009. Vol. 8. No. 4. Pp. 559-573.

13. Torrente J. Production of creative game-based learning scenarios: a handbook for teachers. ProActive public deliverable. Education and Culture DG. Lifelong Learning Programme, 2010. P. 43. URL: http:// www.ub.edu/euelearning/proactive/documents/handbook_creative_gbl.pdf (accessed 14 December 2018). 


\section{СВЕДЕНИЯ ОБ АВТОРАХ}

Московская Наталия Леонидовна, доктор педагогических наук, профессор, заведующий кафедрой романо-германской филологии и лингводидактики Гуманитарного института Северо-Кавказского федерального университета. E-mail: mosknl $\propto$ mail.ru

Перова Елена Александровна, аспирант кафедры романо-германской филологии и лингводидактики Гуманитарного института Северо-Кавказского федерального университета. E-mail: alenaaperova@gmail.com

\section{INFORMATION ABOUT AUTHORS}

Natalia Moskovskaya, Doctor of Pedagogical Sciences, Professor, Head of the Department of Romance \& Germanic Philology \& Linguodidactics, the Institute of Humanities, North Caucasus Federal University. E-mail: mosknl@mail.ru

Elena Perova, post-graduate student of the Department of Romance \& Germanic Philology \& Linguodidactics, the Institute of Humanities, North Caucasus Federal University. E-mail: alenaaperova@gmail.com 